and awareness of, the project. Additional interviews were gathered from former staff and volunteers. Around 50 interviews have been gathered from a diverse range of people involved in the hospice's development from the first clinical staff and volunteers, to those who supported with initial fundraising events and families who received care over the past 35 years. The audio interviews have been shared on our website, alongside archive BBC footage. A multi-media exhibition is being shown at events throughout the year.

Results During the first staging of the exhibition, former staff and volunteers were reconnected through their collective memories and people were educated about our hospice's development. It has provided further opportunities to communicate about our work and future plans, and equipped volunteers with new skills.

Conclusions We now have a repository where many precious memories form a lasting legacy, capturing the story of our hospice for a much wider audience and for future generations.

\section{P-40 A MATTER OF LIFE AND DEATH: LEADING CONVERSATIONS FROM THE FRINGE}

Sharon Hudson. Birmingham St Mary's Hospice, Birmingham, UK

\subsection{6/bmispcare-2017-hospice.67}

What's it all about? BrumYODO is a collaborative of citizens from across the arts, health, death industry and much more. Above all we are citizens of Birmingham who create opportunities to bring conversations about death and dying out into public spaces.

Our evolution We began from a small conversation in a pub (all the best conversations are) about a Death Café three years ago. This year we ran a festival - 'A Matter of Life and Death'- in Dying Matters Week. It was a vibrant, multifocused event in the heart of Birmingham, composed of creative arts, films, photography, theatre and talks tackling difficult topics. We are all volunteers and this year received funding from the Arts Council. Evaluation is still in process but footfall, engagement and attendance were extraordinary. Many conversations were had about life, death, hope and creativity. So how is this leadership? Free from the boundaries of organisations and systems our little team are free to create. It has brought together new networks, connecting those who worked in parallel. It has freed the creative aspects of ourselves and in doing so stretched 'What is possible'. It has generated something which feels owned by Birmingham and its citizens.

So what now? We believe we have a social commitment. The need for meaningful conversation and action for end of life care is real and now. We wish to create bigger networks of communities who return the focus of end of life care back to people.

\section{P-41 A COMMUNITY ENGAGEMENT APPROACH TO TALKING ABOUT DEATH, DYING, BEREAVEMENT AND MAKING PLANS FOR THE END OF LIFE}

Margaret Brown. St Giles Hospice, Lichfield, UK
Pop Up Shop held during Dying matters Week 2017 'Our lack of openness has affected the quality and range of support and care services available to patients and families.' Dying Matters website.

Aim To engage with the local community in conversations relating to death, dying, bereavement and end of life plans, using a Pop Up shop in the centre of town on the three main market days.

What We did

- We partnered with our local Co-operative Funeral Service, who had premises we could use, and invited a number of relevant local organisations to join us in reaching out to our local community.

- Offered café style space with free tea, coffee, cakes etc.

- Provided wide range of local information relating to death, dying, bereavement and advance care planning.

- Offered complementary therapy taster sessions.

- The Co-op provided a white coffin for people to decorate with pictures, messages etc.

What We Learnt

- People highly valued our time in listening to them.

- People sometimes need 'permission' to talk about things that concern them.

- The public value seeing local organisations working together.

- The importance of using local people to engage with local people.

- As a hospice we couldn't have done it on our own.

Unexpected Outcomes

- Recruitment of new volunteers and interest in joining the wider health and social care workforce.

- Quality and depth of conversations that took place both inside and outside the shop.

- Enhanced our partnership working; strengthened relationships, increased knowledge and understanding of each other's services.

- People said they valued seeing us model that it's possible to approach difficult subjects without causing offence.

- Support from other departments within the hospice which has helped us in reaching our internal community with the key messages from the Dying Matters agenda.

- Income generation - people insisting on giving us money despite us being clear in not asking for donations.

\section{P-42 THE MILL AT ST CATHERINE'S PARK, CAFÉ AND COMMUNITY HUB - THE FIRST THREE YEARS}

Lynn Kelly. St Catherine's Hospice, Lancashire, UK

10.1136/bmjspcare-2017-hospice.69

Background The Mill opened on 24 November 2014 as a café and community hub providing a reassuring and welcoming space for families and patients, an information and signposting service through volunteers, opportunities for income generation through room hire plus diversional activities such as light exercise classes, crafts and talking therapies.

Aims To serve the whole population by encouraging and empowering people to help each other. To demystify hospice care. To develop sustainable income streams through commercial and community involvement.

Methods New volunteer positions: Café Assistant table service and Advisor Service for signposting, information and basic 
emotional support. Autumn 2015 - core café opening hours set at 9 am to $5 \mathrm{pm}$ following pilots for breakfast and evening trade. Room hire - two upstairs rooms hired out on long term let plus one larger room for ad hoc bookings (light exercise classes, business meetings, special occasions e.g., wakes, christenings, and birthdays). The Mill Outside - outside catering service started summer 2015; attends country shows, special occasions and hospice events. Special Christmas events e.g., themed afternoon tea, party bookings, tea with Father Christmas from 2015. Patient education programme, STREAM, for cancer related fatigue - open to non-hospice patients - started March 2016. Introduced monthly evening theme nights in May 2016 - Tapas, French, Seafood, World Curry.

Results Include Since opening in Nov 2014 to end of the last financial year: Percentage increase in income and visitors per day: café sales by $88 \%$; donations via The Mill to the hospice by $167 \%$; visitors to the café by $61 \%$. Advisors support as many people that are not known to the hospice as are known. Patient outcomes for STREAM programme using the Chalder Fatigue Scale $-86 \%$ felt their fatigue had improved. Promotional competition for afternoon tea vouchers reaches 79000 people.

The Future Plans for The Mill Phase 2 include expansion of the café to provide extra seating at busy times, two additional function rooms and increased trading opportunities.

\section{P-43 ENGAGING COMMUNITIES IN LIFE AND DEATH CONVERSATIONS}

Ian Leech. St Giles Hospice, Lichfield, UK

\subsection{6/bmispcare-2017-hospice.70}

Background As part of our commitment to create Compassionate Communities we have developed a series of Conversation Boards to enable people, not only to talk but also to think about conversations relating to death, dying and bereavement.

Aims To engage our communities in non-pressurised conversations around death, dying and bereavement and create a place for related literature to be available.

Method Each year we ask our communities a different question, the answers are then placed on a board alongside relevant materials that viewers of the board can freely take. Before I die, I want to .... Inspired by Candy Chang, our first life and death conversation in 2014 asked people of all ages across our communities what is top of their bucket list.

I Want to be Remembered In 2015 we asked people how they wanted to be remembered or what they wanted to be remembered for. My funeral song. Music plays a big part in peoples' lives so for 2016 we asked people to choose the one song they would want to be played at their funeral. What makes life worth while. We often talk of care being centred on the person, but to do that we have to discover what matters to those people we care for.

Results Since 2014 this project has enabled hundreds of timely conversations in a way that suits each individual. Over 100 pieces of death, dying and bereavement related literature is taken each month.

Conclusion Not everyone is comfortable talking about death, but in our conversation boards, we have found a way not only to communicate with people on their terms. It has helped us to discover what is important to people in our community and made us think about how we can realise their wishes.

\section{P-44 COMMUNITY ENGAGEMENT NETWORKS}

Vicky Lander. Oakhaven Hospice Trust, Lymington, UK

10.1136/bmispcare-2017-hospice.71

Earlier this year, St Richard's Hospice and St Giles Hospice, both located in the The Midlands, joined forces to instigate a network of those people employed in hospices with the remit and title of Community Engagement. After a successful gathering in February at St Giles, the initiative has gone from strength to strength with another Midlands network held in May. In addition, as a guest member of the Midlands group, being based at Oakhaven Hospice in Hampshire, I took up the challenge to set up a similar network for hospices along the South Coast. This has proved equally successful with a number of hospices contributing to our first forum in June. The networks are aimed at raising awareness, increasing understanding and accessing seldom heard groups in hospice care and not necessarily community fundraisers, unless the remit of the role encompasses both. Bringing hospices' staff together, specifically people whose remit is titled Community Engagement, yet with a plethora of interpretations of the title, has proved valuable for sharing learnings, debating topics and building on new ideas. This initiative of Networks dovetails into the Hospice UK strategy goal no.3 'strive to build community capacity and resilience to care for those at the end of life' and we are keen to promote other regions to follow our lead. Our poster is aimed to encourage conference attendees to consider how they might take forward the Community Engagement network initiative for their regions.

\section{P-45 LEEDS COMPASSIONATE COMMUNITIES - IMPROVING END OF LIFE CARE FOR ALL}

Peter McEvoy. St. Gemma's Hospice, Leeds, UK

\subsection{6/bmjspcare-2017-hospice.72}

Background We are receiving 50\% fewer clinical referrals from Black Asian Minority Ethnic (BAME) communities in the Leeds 7 and 8 postcode areas compared to LS17. We had insufficient evidence to substantiate the specific needs of local BAME communities. A Third Sector Health Grant funded a research project to understand more fully the issues and barriers around communication and language, culture and religion.

Aims The project aimed to improve the support, access and care provided at a person's end of life by ensuring that St. Gemma's services are accessible and culturally appropriate for the BAME communities living in the LS7 and LS8 areas of Leeds.

Methods Developed innovative working relationship with Leeds Involving People (LIP) a service-user led organisation specialising in connecting citizen insight with service redesign. We commissioned LIP to engage with and conduct a survey across BAME community groups to gather quantitative responses and undertake specific focus group work to gain more qualitative responses from harder to reach communities. 